\title{
PSAP gene variants and haplotypes reveal significant effects on carcass and meat quality traits in Chinese Simmental-cross cattle
}

\author{
Pengcheng Guo ${ }^{1}$, Zhihui Zhao ${ }^{1}$, Shouqing Yan $^{1}$, Junya $\mathrm{Li}^{2}$, Hang Xiao ${ }^{1}$, Dongxue Yang ${ }^{1}$, Yaolu Zhao ${ }^{1}$, \\ Ping Jiang ${ }^{1}$, and Runjun Yang ${ }^{1}$ \\ ${ }^{1}$ College of Animal Science, Jilin University, Xi'An Road 5333, Changchun, 130062 Jilin, China \\ ${ }^{2}$ Institute of Animal Sciences, Chinese Academy of Agricultural Sciences, 100193 Beijing, China
}

Correspondence to: Runjun Yang (yrj@jlu.edu.cn)

Received: 3 August 2016 - Revised: 25 October 2016 - Accepted: 3 November 2016 - Published: 14 November 2016

\begin{abstract}
Prosaposin (PSAP) is the precursor protein of four small lysosomal glycoproteins and plays vital roles in muscle growth and development of beef cattle. The aim of this study is to evaluate the association between PSAP gene polymorphisms with carcass composition and meat quality traits of Chinese Simmental-cross cattle. In the present study, six SNPs were identified within intron 10 and exon 11 of the PSAP gene from 380 beef cattle by direct DNA sequencing, and 47 traits of carcass composition and meat quality were measured in the studied population. Then, the relationship between variants of PSAP gene with economic traits was analyzed using statistical methods. The result revealed that I10-65G $>$ A, I10-313C $>$ T, E11-87C $>$ T, and E11-93C $>$ G were significantly associated with carcass traits, such as dressing percentage, fat coverage rate, carcass depth, and hind leg width, and I10-162C $>\mathrm{T}$ and I10-274C $>\mathrm{T}$ were significantly associated with marbling score traits. In addition, the individuals with GCCCGC haplotype showed significant higher dressed weight, dressing percentage and rib eye area $(p<0.01)$, and the individuals with ACCTCC haplotype showed a significant association with the $\mathrm{pH}$ of beef and backfat thickness in the cattle population $(p<0.05)$. Our results indicate that these SNPs and haplotypes of the PSAP gene are possible important genetic factors that influence carcass composition and meat quality traits, and they may be useful markers in future marker-assisted selection (MAS) programs in beef cattle breeding and production.
\end{abstract}

\section{Introduction}

Despite advances in the identification of genetic variants that affect economic traits of livestock, identifying DNA polymorphisms that contribute to meat quality and carcass traits in cattle remains a challenge (Gill et al., 2009). A better understanding of DNA polymorphisms that have an effect on carcass and meat quality could lead to important applications, permitting us to adapt bovine carcass and meat quality traits to consumer and market demands through markerassisted selection (MAS) programs.

The bovine prosaposin (PSAP) gene is located on chromosome 10 and contains 15 exons, in which exon 8 has the shortest length of only nine base pairs (Zhao and Morales, 2000). Prosaposin, a $65-70 \mathrm{kDa}$ glycoprotein, is the precur- sor for four sphingolipid activator proteins: saposins A, B, C, and D (Morales et al., 1995, 1998; Zhao et al., 1998). PSAP mRNA can be transcribed into two major isoforms, which differ in the inclusion of exon 8, encoding three extra amino acids, Gln-Asp-Gln, within the saposin B domain (Zhao et al., 1997). And tissue-specific alternative splicing in the PSAP mRNA is conserved from fish to human (Cohen et al., 2004). Studies have found PSAP mRNA in the testes, lungs, pancreas, spleen, and kidneys almost always excludes exon 8 ; the transcript containing exon 8 is mainly distributed in the brain, heart, and skeletal muscle (Zhao et al., 1997; Lamontagne and Potier, 1994). Prosaposin has two distinct profiles: one is a precursor hydrolyzed to four saposins that are indispensable cofactors for the intralysosomal degradation of a number of sphingolipids within the 
lysosome (Hirabayashi et al., 1983); the other acts as an important secretory protein that is not processed into saposins, and exists in various bodily fluids such as breast milk, cerebrospinal fluid, and sperm (Kishimoto et al., 1992). Moreover the latter has important functions in the nervous system (Hiraiwa et al., 1999), oxidative stress (Panigone et al., 2001), improving the ability of bull sperm (Amann et al., 1999), male reproductive system (Morales et al., 2000), and oncogenic processes (Morales et al., 2000; Campana et al., 1996). Interestingly, sphingolipid catabolism generates lipophilic intermediates (ceramide, sphingosine, and sphingosine 1-phosphate, among others), which are involved in the transmission of extracellular signals to intracellular regulatory systems (Hannun and Obeid, 2008). For example, ceramide mediates anti-mitogenic effects such as cell differentiation, cell cycle arrest, and cell senescence (Hannun and Obeid, 2008; Haimovitz-Friedman et al., 1997). Although numerous studies have implicated that prosaposin is essential for many metabolic processes, no evidence indicates that the $P S A P$ gene is associated with cattle carcass and meat quality traits. The investigation of PSAP gene polymorphisms is of great interest because it might be associated with carcass and meat quality traits.

As the PSAP gene was hypothesized as a candidate gene, the objectives of this study were to determine the correlation between PSAP gene polymorphisms and meat quality traits in Chinese Simmental-cross cattle population. And the results may provide a basis for MAS in the processes of pure breeding, crossbreeding, and preserving important genetic resources.

\section{Materials and methods}

In the experiment, 380 Chinese Simmental-cross cattle that were crossbred with Simmental-bull frozen semen were randomly selected from 15 cattle farms in Wulagai animal husbandry management district of Xilin Gol league in Inner Mongolia. All economic traits (carcass traits and meat quality traits) of beef cattle were performed at the Inner Mongolian Baolongshan beef cattle slaughterhouse and the Chinese Academy of Agricultural Sciences meat laboratory (Tian et al., 2013). Animal experiments were performed in strict accordance with the guide for care and use of laboratory animals by the Jilin University animal care and use committee (permit number: SYXK, 2012-0010/0011).

\subsection{Blood collection and DNA sample preparation}

For this study, the blood samples $(10 \mathrm{~mL}$ each) of 28-monthold Chinese Simmental-cross cattle were collected from the jugular vein with anticoagulant (acid citrate dextrose; ACD) and stored at $-70^{\circ} \mathrm{C}$. Genomic DNA was extracted from leukocytes of whole blood using AxyPrep ${ }^{\mathrm{TM}}$ Blood Genomic DNA Miniprep Kit according to the manufacturer's protocol.

\subsection{Trait analyses}

All standardized carcass and meat quality assessments were performed at the Chinese Academy of Agricultural Sciences meat laboratory and molecular genetic laboratory of Jilin University (Fang et al., 2014).

The carcasses were stored in refrigerated rooms at a temperature between 0 and $4{ }^{\circ} \mathrm{C}$ for $24 \mathrm{~h}$. Then, all the carcass and meat traits were assessed based on the GB/T17238-1998 cutting standard of fresh and chilled beef criterion of China (China Standard Publishing House).

For analysis, the dressed weight (DW), dressing percentage (DP), net weight of bone (NWB), kidney fat weight (KFW), $\mathrm{pH}$ value of carcasses $(\mathrm{PH})$, carcass length (CL), carcass depth (CD), carcass brisket depth (CBD), hind leg circumference (HLC), hind leg width (HLW), thigh meat thickness (TMT), thickness of loin (TL), backfat thickness (BFT), fat coverage rate of the carcass (FCR), marbling score (MBS), rib eye area (REA), muscle color score (MCS), and fat color score (FCS) were recorded.

\subsection{PCR amplification, sequencing and SNP detection}

A primer pair was designed from the published bovine $P S A P$ gene sequence (GenBank accession number: AC_000185.1) by using the Oligo 6 program. The primer sequences are as follows: forward, 5'-TTACTGCGAGGTGTGCGAGTT-3'; reverse, 5'-CCTCGGCATCACACGGACT-3'. Polymerase chain reaction (PCR) was performed in a $50 \mu \mathrm{L}$ total volume of the following mixture: $100 \mathrm{ng} \mathrm{mL}^{-1}$ bovine genomic DNA, $2 \mu \mathrm{L} ; 10 \mathrm{pmol} \mathrm{L}^{-1}$ of each primer, $1 \mu \mathrm{L}$ each; and $2 \times$ Taq PCR Green Mix (Beijing Dingguo Changsheng Biotechnology Co. Ltd.), $25 \mu \mathrm{L}$. Fragment amplification was performed as follows: initial denaturation at $94^{\circ} \mathrm{C}$ for $5 \mathrm{~min}$; 30 cycles of $94^{\circ} \mathrm{C}$ for $30 \mathrm{~s}$, annealing at $63^{\circ} \mathrm{C}$ for $30 \mathrm{~s}$, and $72^{\circ} \mathrm{C}$ for $40 \mathrm{~s}$; and a final extension at $72^{\circ} \mathrm{C}$ for $10 \mathrm{~min}$.

The PCR products were purified and sequenced in the automated ABI PRISM 3100 Genetic Analyzer sequencer (Applied Biosystems, Foster City, California, USA). The SNPs in the PSAP gene were identified through sequences aligned by SeqMan (DNASTAR, Inc., Madison, Wisconsin, USA).

\subsection{Statistical analysis}

Allelic and genotypic frequency values, genetic indices of polymorphism information contents (PICs), were calculated. The Hardy-Weinberg equilibrium of the polymorphisms was determined by the chi-squared $\left(\chi^{2}\right)$ test. The association between PSAP gene polymorphisms and carcass and meat quality traits was analyzed by two-way analysis of variance (ANOVA) using SPSS 13.0 for Windows. The fixed model was

$Y_{i j k}=u+\mathrm{ys}_{i}+m_{j}+e_{i j k}$,

where $Y_{i j k}$ is the observed value of the $k$ th individual from the Simmental breed of genotype $j$ in the $i$ th-year season, 


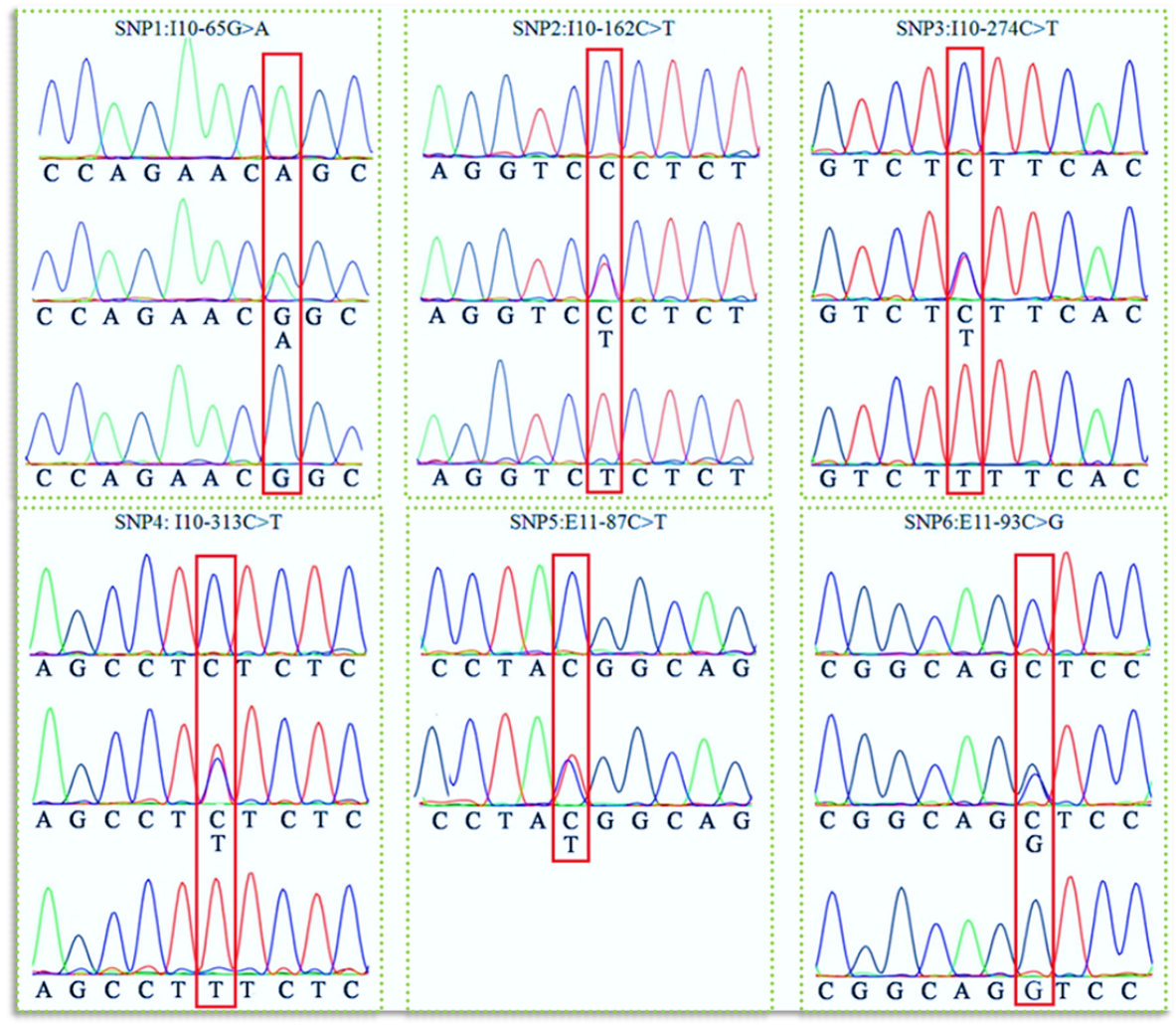

Figure 1. DNA sequencing for the individual Chinese Simmental-cross cattle population.

$u$ is the lowest square mean of the observed values, $\mathrm{ys}_{i}$ is the effective value of the $i$ th-year season, $m_{j}$ is the effective value of genotype $j$, and $e_{i j k}$ is the random residual effect corresponding to the observed value. Based on the six SNPs, haplotypes, and their frequencies were inferred using the algorithm developed by Stephens et al. (2001).

\section{Results}

\subsection{Polymorphisms identified by PSAP gene sequencing}

The PCR products were consistent with the target fragment and had good specificity. By direct DNA sequencing, four SNP tags were identified in intron 10 of the PSAP gene: I10$65 \mathrm{G}>\mathrm{A}($ Ensembl rs42143937), I10-162C $>\mathrm{T}$ (Ensembl rs381104888), I10-274C > T (Ensembl rs385887193), I10313C > T (Ensembl rs209315330); and two SNPs were identified in exon 11: E11-87C $>\mathrm{T}$, which induced a synonymous mutation, and E11-93C > G (Ensembl rs133441330), which induced a missense mutation of Ser (AGC) to Arg (AGG). All the SNPs are found in the NCBI dbSNP database, except for E11-87C $>\mathrm{T}$, which is different from the SNP of rs432651539 that induces a stop-gain mutation. DNA sequencing maps are shown in Fig. 1.

\subsection{Genetic diversity of the PSAP gene in Chinese Simmental population}

After six SNPs were selected for genotyping, the allele frequency, genotype frequency, homozygosity, heterozygosity, and effective allele numbers were analyzed in the population (Table 1). According to the data, the frequencies of wild type alleles were all higher than of the mutant alleles. Statistical analysis revealed that the ranges (from SNP I10-65G $>$ A to E11-93C > G) of homozygosity, heterozygosity, and effective allele numbers of six SNPs were 0.579 to $0.976,0.024$ to 0.421 , and 1.025 to 1.727 , respectively.

The values of genetic diversity and characteristics, including PICs and $\chi^{2}$ values, are shown in Table 1 . The PICs ranged from 0.0234 to 0.3409 , indicating that $\mathrm{I} 10-313 \mathrm{C}>\mathrm{T}$ and $\mathrm{E} 11-87 \mathrm{C}>\mathrm{T}(\mathrm{PIC}<0.25)$ had low polymorphism, the other four SNPs $(0.25<$ PIC $<0.5)$ had intermediate polymorphism. According to $\chi^{2}$ tests, four SNPs fit the HardyWeinberg equilibrium in the population $(P>0.05)$, whereas two SNPs did not $(p<0.05)$ (Fig. 2).

\subsection{Linkage disequilibrium and haplotype construction}

Although 16 haplotypes were constructed based on the six contiguous SNPs identified from the population of $380 \mathrm{Chi}-$ nese Simmental-cross cattle, only six haplotypes with frequencies greater than 0.03 were selected for association anal- 
Table 1. Genotypes, allele frequencies, and population genetic indexes of six PSAP gene polymorphisms in 380 Chinese Simmental-cross cattle. PIC is the polymorphism information content. HWE is the Hardy-Weinberg equilibrium.

\begin{tabular}{|c|c|c|c|c|c|c|c|c|}
\hline \multirow[t]{2}{*}{ Loci } & \multirow{2}{*}{$\begin{array}{l}\text { Allele } \\
\text { frequency }\end{array}$} & \multirow{2}{*}{$\begin{array}{l}\text { Genotype } \\
\text { frequency }\end{array}$} & \multirow[t]{2}{*}{ Homozygosity } & \multirow[t]{2}{*}{ Heterozygosity } & \multirow{2}{*}{$\begin{array}{r}\text { Effective } \\
\text { allele numbers }\end{array}$} & \multirow[t]{2}{*}{ PIC } & \multicolumn{2}{|c|}{ HWE } \\
\hline & & & & & & & $\chi^{2}$ & $p$ \\
\hline $\mathrm{I} 10-65 \mathrm{G}>\mathrm{A}$ & $\begin{array}{l}\mathrm{G}(0.679) \\
\mathrm{A}(0.321)\end{array}$ & $\mathrm{GG}(0.468) \mathrm{GA}(0.421)$ & 0.579 & 0.421 & 1.727 & 0.3409 & 0.444 & 0.505 \\
\hline I10-162 C $>$ T & $\begin{array}{l}\mathrm{C}(0.782) \\
\mathrm{T}(0.218)\end{array}$ & $\begin{array}{l}\mathrm{CC}(0.589) \mathrm{CT}(0.384) \\
\mathrm{TT}(0.026)\end{array}$ & 0.616 & 0.384 & 1.623 & 0.2828 & 5.967 & 0.015 \\
\hline I10-274 C > T & $\begin{array}{l}\mathrm{C}(0.795) \\
\mathrm{T}(0.205)\end{array}$ & $\begin{array}{l}\mathrm{CC}(0.613) \mathrm{CT}(0.363) \\
\mathrm{TT}(0.024)\end{array}$ & 0.637 & 0.363 & 1.570 & 0.2728 & 4.860 & 0.028 \\
\hline I10-313 C > T & $\begin{array}{l}\mathrm{C}(0.832) \\
\mathrm{T}(0.168)\end{array}$ & $\begin{array}{l}\mathrm{CC}(0.689) \mathrm{CT}(0.284) \\
\mathrm{TT}(0.026)\end{array}$ & 0.716 & 0.284 & 1.397 & 0.2405 & 0.081 & 0.775 \\
\hline E11-87 C > T & $\begin{array}{l}\mathrm{C}(0.988) \\
\mathrm{T}(0.012)\end{array}$ & $\begin{array}{l}\mathrm{CC}(0.976) \mathrm{CT}(0.024) \\
\mathrm{TT}(0.000)\end{array}$ & 0.976 & 0.024 & 1.025 & 0.0234 & 0.055 & 0.815 \\
\hline E11-93 C > G & $\begin{array}{l}\mathrm{C}(0.811) \\
\mathrm{G}(0.189)\end{array}$ & $\begin{array}{l}\mathrm{CC}(0.663) \mathrm{CG}(0.295) \\
\mathrm{GG}(0.042)\end{array}$ & 0.705 & 0.295 & 1.418 & 0.2596 & 0.620 & 0.431 \\
\hline
\end{tabular}

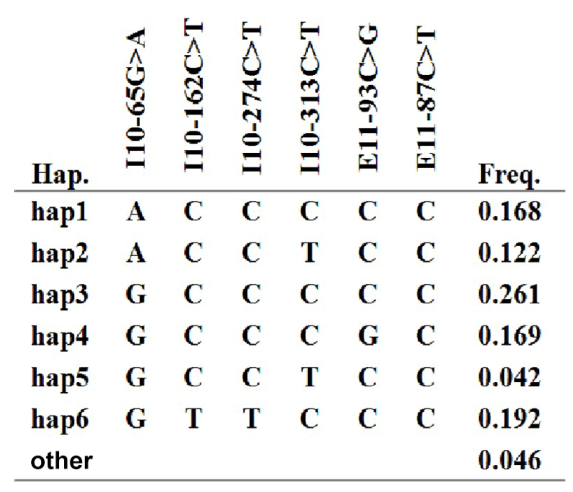

(a) Haplotypes in PSAP

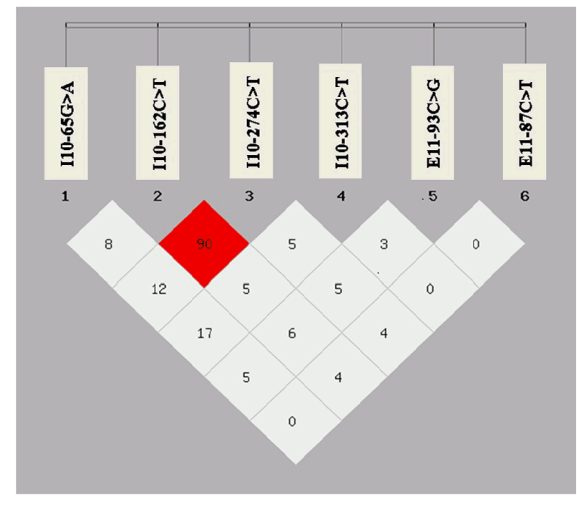

(b) LDs among PSAP polymorphism

Figure 2. Gene haplotype and linkage disequilibrium (LD) coefficients in PSAP gene. (a) Haplotypes of PSAP. Haplotypes with a frequency greater than 0.03 are presented. Others contain rare haplotypes. (b) Linkage disequilibrium coefficient $\left(D^{\prime}\right.$ and $\left.r^{2}\right)$ among $P S A P$ polymorphisms. The numbers are $r^{2}$ values $(\%)$.

ysis (Fig. 2a). Linkage disequilibrium between polymorphism pairs and haplotype structure analysis of SNPs in the studied population are shown in Fig. 2b. From the analysis result of linkage disequilibrium (LD), it is a tight $\mathrm{LD}$ $\left(r^{2}>0.33\right)$ between $\mathrm{I} 10-162 \mathrm{C}>\mathrm{T}$ and $\mathrm{I} 10-274 \mathrm{C}>\mathrm{T}$, and other pairs of SNPs are weak LDs $\left(r^{2}<0.33\right)$ with each other.

\subsection{Association analyses of PSAP polymorphisms with carcass and meat quality traits}

The relationships among the genotypes of 380 individuals and 18 carcass and meat quality traits were analyzed (Table 2). According to the statistical analysis, the SNPs I10$65 \mathrm{G}>\mathrm{A}, \mathrm{I} 10-313 \mathrm{C}>\mathrm{T}, \mathrm{E} 11-87 \mathrm{C}>\mathrm{T}$, and $\mathrm{E} 11-93 \mathrm{C}>\mathrm{G}$ were significantly associated with carcass traits, and the SNPs I10-162C $>\mathrm{T}$ and I10-274C $>\mathrm{T}$ were significantly associated with carcass and meat quality traits. The HLC, BFT, and FCR $(p<0.01)$, and DW $(p<0.05)$ were found to be significantly associated with the $\mathrm{I} 10-65 \mathrm{G}>\mathrm{A}$ in the present population. Cattle with the genotype GA have higher HLC, BFT, FCR, and DW than cattle with the GG and AA genotypes. As a tag SNP marker, I10-162C $>\mathrm{T}$ was found to be significantly associated with CD $(p<0.01)$ and NWB, PH, CL, CBD, HLW, TL, FCR, and FCS $(p<0.05)$ in the present population. In detail, cattle with the genotype $\mathrm{CC}$ have higher NWB, PH, CBD, HLW, and FCS than cattle with the CT genotype ( $p<0.05)$, moreover, the genotype CT have higher TL than those with the CC genotype $(p<0.05)$. For I10-274C $>$ T, significant correlation was found with the TL, BFT, and FCR $(p<0.01)$, and NWB and CD $(p<0.05)$ in the present population. Cattle with the genotype CT tended to have higher BFT and FCR than those with the genotypes TT $(p<0.01)$ and CC $(p<0.05)$, and the genotype CT tended to have a higher TL than those with the genotype CC $(p<0.01)$. In contrast, cattle with the genotype CC 


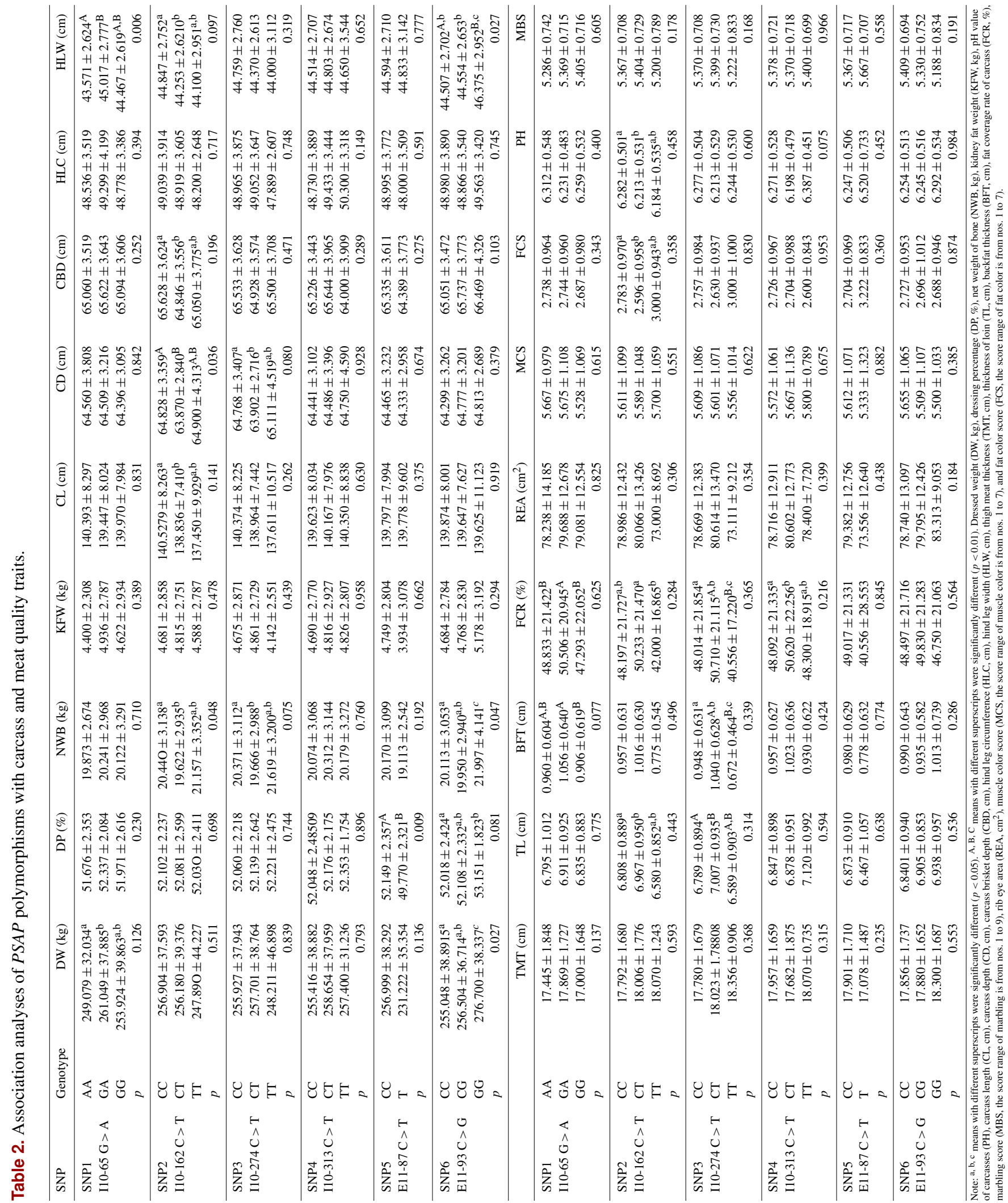


Table 3. Association of haplotypes ( $\mathrm{HF}>0.03)$ with carcass and meat quality traits of the cattle population.

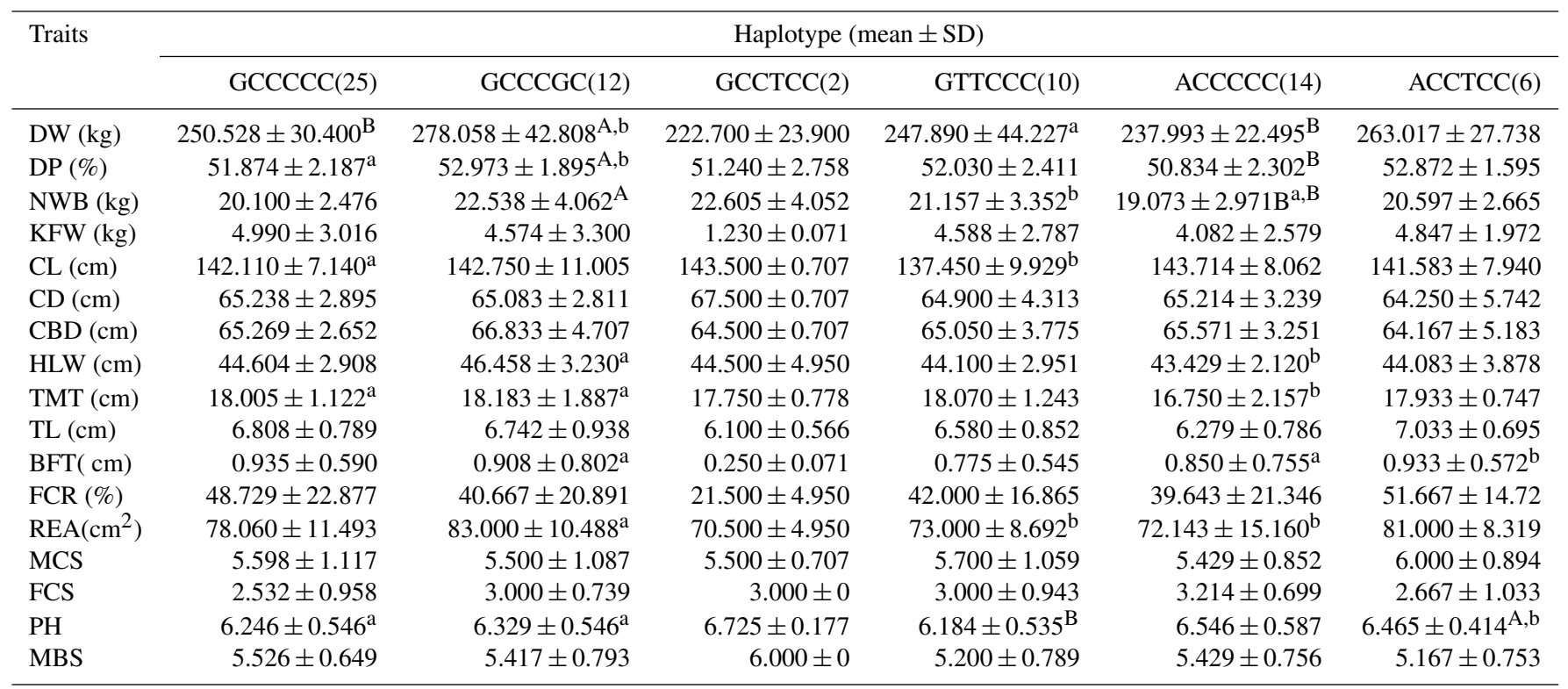

Note: ${ }^{\mathrm{a}, \mathrm{b}, \mathrm{c}}$ means with different superscripts were significantly different $(p<0.05)$. A, B, C means with different superscripts were significantly different $(p<0.01)$. Dressed weight (DW, kg), dressing percentage (DP, \%), net weight of bone (NWB, $\mathrm{kg}$ ), kidney fat weight (KFW, $\mathrm{kg}$ ), pH value of carcasses (PH), carcass length (CL, cm), carcass depth (CD, cm), carcass brisket depth (CBD, cm), hind leg circumference (HLC, cm), hind leg width (HLW, cm), thigh meat thickness (TMT, cm), thickness of loin (TL, cm), backfat thickness (BFT, cm), fat coverage rate of carcass (FCR, \%), marbling score (MBS, the score range of marbling is from nos. 1 to 9), rib eye area (REA, $\mathrm{cm}^{2}$ ), muscle color score (MCS, the score range of muscle color is from nos. 1 to 7), and fat color score (FCS, the score range of fat color is from nos. 1 to 7 ).

had higher NWB and CD than those with the genotype CT $(p<0.05)$. Furthermore, cattle with the genotype CC tended to have higher BFT and FCR than those with the genotype TT $(p<0.05)$. About I10-313C $>$ T, cattle with the genotype CT had higher FCR than those with the genotype CC $(p<0.05)$. For E11-87C $>\mathrm{T}$, cattle with the genotype CC had higher DP than those with the CT genotype $(p<0.01)$. The last E11-93C $>\mathrm{G}$ was significantly associated with DW, DP and NWB $(p<0.05)$ and the HLW $(p<0.01)$ in the present population. With detailed description, cattle with the genotype GG had higher DW, DP, and NWB than those with the genotype CC $(p<0.05)$; and the genotype GG had higher DW and NWB values than those with the genotype CG $(p<0.05)$. In contrast, cattle with the genotype GG had higher HLW than those with the genotypes CC $(p<0.01)$ and CG $(p<0.05)$.

Six haplotypes constructed from six contiguous SNPs were analyzed to assess the relationship between the genotypes and phenotypes of 69 individuals. As analysis results revealed, haplotypes were significant with DW, DP, NWB, and PH $(p<0.01)$, and CL, HLW, TMT, BFT, and REA $(P<0.05)$ (Table 3). In particular, the GCCCGC haplotype tended to have higher DW, DP, and NWB than those with the ACCCCC haplotype $(p<0.01)$, and the ACCTCC haplotype tended to have a higher $\mathrm{pH}$ than those with the GTTCCC haplotype $(p<0.01)$.

\section{Discussion}

Meat quality is commercially important for the animal husbandry industry and is affected by genetic background, management, nutrition and meat processing (Boukha et al., 2011; Cherel et al., 2012). As an exocrine or endocrine protein, prosaposin has important effects on many metabolic processes. No studies have reported an association between the PSAP gene and economic traits, which therefore stimulated our interest in this research.

In the present study, we identified six contiguous polymorphisms in the PSAP gene from 380 Chinese Simmental-cross cattle, and population genetic indexes as well as LD coefficients were analyzed. The disequilibrium may have resulted from the use of frozen bull semen as well as from the high selection intensity over the past few years. In general, the PIC is closely linked with the number of alleles and their frequency distribution. In the present study, four SNPs with moderate abundance might have resulted from open conservation of the sampling group in recent years.

Our data showed PSAP SNPs of $\mathrm{I} 10-65 \mathrm{G}>\mathrm{A}$, I10$313 \mathrm{C}>\mathrm{T}$, E11-87C $>\mathrm{T}$, and $\mathrm{E} 11-93 \mathrm{C}>\mathrm{G}$ were significantly associated with carcass traits, while SNPs of I10$162 \mathrm{C}>\mathrm{T}$ and $\mathrm{I} 10-274 \mathrm{C}>\mathrm{T}$ were significantly associated with carcass and meat quality traits. Four polymorphisms (I10-65G $>$ A, I10-313C $>$ T, I10-162C $>$ T, I10-274C $>$ T) are non-coding mutations, which do not result in a change in the amino acid sequence of the protein. However, intronic mutations may affect gene regulation, altering the phenotype 
through aberrant splicing (Shastry, 2009; Komar, 2007). For example, the IGF2 intron 3-G3072A mutation has major effects on muscle growth, heart size, and fat deposition (Van Laere et al., 2003). Although the E11-87C $>$ T mutation is a synonymous mutation that does not affect the amino acid sequence of the protein, increasing evidence indicates that this mutation could still affect transcription, splicing, mRNA transport or translation - any of which could result in phenotypic alteration (Goymer, 2007). The E11-93C > G mutation is a missense mutation in the coding region, and this type of mutation could change the amino acid sequence of the protein, thereby potentially affecting the translational efficiency and altering its function, which appears to be a trend in controlling the carcass and meat quality traits in the Chinese Simmental-cross cattle population. These observations stimulate interest in identifying the mechanism of how these types of mutations affect carcass and meat quality traits in beef cattle.

According to the statistical results, individuals with the GCCCGC haplotype have higher DW, DP, and NWB $(p<0.01)$ as well as HLW, TMT, and REA $(p<0.05)$ than those with the other haplotypes. Therefore, the GCCCGC haplotype might be a molecular marker of combined genotypes for cattle seed selection in the future. Comparing methods based on single SNP analysis and haplotype-based analysis, the latter can provide a more powerful assessment of the complex relationship between genetic variation and phenotypes. Thereby, haplotype combination analysis is more effective than single SNP analysis.

In summary, the PSAP gene has potential effects on carcass and meat quality traits in the Chinese Simmental-cross cattle population. Based on the results of the biologically relevant genotype-phenotype associations, PSAP gene polymorphisms may be applicable to MAS in breeding programs for beef cattle in China. Further functional research is required to clarify the mechanism of how these PSAP gene polymorphisms effect carcass and meat quality traits.

\section{Data availability}

The original data are available upon request to the corresponding author.

Acknowledgements. This work was supported by the National High Technology Research and Development Program of China (no. 2013AA102505), the National Natural Science Foundation of China (nos. 31372278 and 31672389), the National Research and Development Project of Transgenic Organisms of the Ministry of Science and Technology, China, (2014ZX0800953B), and the provincial industrial innovation special foundation of Jilin province (2016C032).

Edited by: S. Maak

Reviewed by: two anonymous referees

\section{References}

Amann, R. P., Seidel Jr., G. E., and Brink, Z. A.: Exposure of thawed frozen bull sperm to a synthetic peptide before artificial insemination increases fertility, J. Androl., 20, 42-46, 1999.

Boukha, A., Bonfatti, V., Cecchinato, A., Albera, A., Gallo, L., Carnier, P., and Bittante, G.: Genetic parameters of carcass and meat quality traits of double muscled Piemontese cattle, Meat Sci., 89, 84-90, doi:10.1016/j.meatsci.2011.03.024, 2011.

Campana, W. M., Hiraiwa, M., Addison, K. C., and O'Brien, J. S.: Induction of MAPK phosphorylation by prosaposin and prosaptide in PC12 cells, Biochem. Bioph. Res. Co., 229, 706-712, doi:10.1006/bbrc.1996.1869, 1996.

Cherel, P., Herault, F., Vincent, A., Le Roy, P., and Damon, M.: Genetic variability of transcript abundance in pig skeletal muscle at slaughter: relationships with meat quality traits, J. Anim. science, 90, 699-708, doi:10.2527/jas.2011-4198, 2012.

Cohen, T., Ravid, L., Altman, N., Madar-Shapiro, L., Fein, A., Weil, M., and Horowitz, M.: Conservation of expression and alternative splicing in the prosaposin gene, Brain research, Mol. Brain Res., 129, 8-19, doi:10.1016/j.molbrainres.2004.06.027, 2004.

Fang, X. B., Zhang, L. P., Yu, X. Z., Li, J. Y., Lu, C. Y., Zhao, Z. H., and Yang, R. J.: Association of HSL gene E1-c.276C > T and E8c.51C > T mutation with economical traits of Chinese Simmental cattle, Mol. Biol. Rep., 41, 105-112, doi:10.1007/s11033-0132842-6, 2014.

Gill, J. L., Bishop, S. C., McCorquodale, C., Williams, J. L., and Wiener, P.: Association of selected SNP with carcass and taste panel assessed meat quality traits in a commercial population of Aberdeen Angus-sired beef cattle, Genet. Sel. Evol., 41, 1-12, doi:10.1186/1297-9686-41-36, 2009.

Goymer, P.: Synonymous mutations break their silence, Nat. Rev. Genet., 8, 92-92, doi:10.1038/nrg2056, 2007.

Haimovitz-Friedman, A., Kolesnick, R. N., and Fuks, Z.: Ceramide signaling in apoptosis, Brit. Med. Bull., 53, 539-553, 1997.

Hannun, Y. A. and Obeid, L. M.: Principles of bioactive lipid signalling: lessons from sphingolipids, Nature reviews, Mol. Cell Biol., 9, 139-150, doi:10.1038/nrm2329, 2008.

Hirabayashi, Y., Li, Y. T., and Li, S. C.: Activator protein for the enzymic hydrolysis of sphingolipids and their relationships to sphingolipidosis, Special reference to the catabolism of GM2 ganglioside, Seikagaku, 55, 1-13, 1983.

Hiraiwa, M., Campana, W. M., Mizisin, A. P., Mohiuddin, L., and O'Brien, J. S.: Prosaposin: A myelinotrophic protein that promotes expression of myelin constituents and is secreted after nerve injury, Glia, 26, 353-360, doi:10.1002/(Sici)10981136(199906)26:4<353::Aid-Glia9>3.0.Co;2-G, 1999.

Kishimoto, Y., Hiraiwa, M., and O'Brien, J. S.: Saposins: structure, function, distribution, and molecular genetics, J. Lipid Res., 33, 1255-1267, 1992.

Komar, A. A.: Silent SNPs: impact on gene function and phenotype, Pharmacogenomics, 8, 1075-1080, doi:10.2217/14622416.8.8.1075, 2007.

Lamontagne, S. and Potier, M.: Modulation of human saposin B sphingolipid-binding specificity by alternative splicing. A study with saposin B-derived synthetic peptides, J. Biol. Chem., 269, 20528-20532, 1994. 
Morales, C. R., el-Alfy, M., Zhao, Q., and Igdoura, S.: Molecular role of sulfated glycoprotein-1 (SGP-1/prosaposin) in Sertoli cells, Histol. Histopathol., 10, 1023-1034, 1995.

Morales, C. R., Hay, N., El-Alfy, M., and Zhao, Q.: Distribution of mouse sulfated glycoprotein-1 (prosaposin) in the testis and other tissues, J. Androl., 19, 156-164, 1998.

Morales, C. R., Zhao, Q., Lefrancois, S., and Ham, D.: Role of prosaposin in the male reproductive system: effect of prosaposin inactivation on the testis, epididymis, prostate, and seminal vesicles, Arch. Andrology., 44, 173-186, 2000.

Panigone, S., Bergomas, R., Fontanella, E., Prinetti, A., Sandhoff, K., Grabowski, G. A., and Delia, D.: Up-regulation of prosaposin by the retinoid HPR and its effect on ceramide production and integrin receptors, FASEB J., 15, 1475-1477, 2001.

Shastry, B. S.: SNPs: impact on gene function and phenotype, Methods Mol. Biol., 578, 3-22, doi:10.1007/978-1-60327-411-1_1, 2009.

Stephens, M., Smith, N. J., and Donnelly, P.: A new statistical method for haplotype reconstruction from population data, Am. J. Hum. Genet., 68, 978-989, doi:10.1086/319501, 2001.

Tian, J., Zhao, Z., Zhang, L., Zhang, Q., Yu, Z., Li, J., and Yang, R.: Association of the leptin gene E2-169T $>C$ and E3-299T $>$ A mutations with carcass and meat quality traits of the Chinese Simmental-cross steers, Gene, 518, 443-448, doi:10.1016/j.gene.2012.11.071, 2013.
Van Laere, A. S., Nguyen, M., Braunschweig, M., Nezer, C., Collette, C., Moreau, L., Archibald, A. L., Haley, C. S., Buys, N., Tally, M., Andersson, G., Georges, M., and Andersson, L.: A regulatory mutation in IGF2 causes a major QTL effect on muscle growth in the pig, Nature, 425, 832-836, doi:10.1038/nature02064, 2003.

Zhao, Q., Hay, N., and Morales, C. R.: Structural analysis of the mouse prosaposin (SGP-1) gene reveals the presence of an exon that is alternatively spliced in transcribed $\mathrm{mR}$ NAs, Mol. Reprod. Dev., 48, 1-8, doi:10.1002/(SICI)10982795(199709)48:1<1::AID-MRD1>3.0.CO;2-N, 1997.

Zhao, Q., Bell, A. W., El-Alfy, M., and Morales, C. R.: Mouse testicular sulfated glycoprotein-1: sequence analysis of the common backbone structure of prosaposins, J. Androl., 19, 165-174, 1998.

Zhao, Q. and Morales, C. R.: Identification of a novel sequence involved in lysosomal sorting of the sphingolipid activator protein prosaposin, J. Biol. Chem., 275, 24829-24839, doi:10.1074/jbc.M003497200, 2000. 